\title{
GIS and Remote Sensing Support in Watershed Conservation and Management: Case Study of the Upper Gucha Watershed - Kenya
}

\author{
Abel Nyaribo Kaburi and Patroba Achola Odera \\ Department of Geomatic Engineering and Geospatial Information Systems Jomo Kenyatta University of \\ Agriculture and Technology
}

\begin{abstract}
Geospatial Information Systems (GIS) and Remote Sensing, and their capability to capture, store, manipulate and display data, have found great utility in the analyses of any spatial phenomena with speed and accuracy anywhere on/above/below the earth surface. One such application is watershed conservation and management. This study demonstrates the role of spatial technologies, in the identification, delineation of river channel network within watersheds, generation of slope and flow direction maps from digital elevation models (DEMs), besides the analyses of impacts by human activities on land cover through land use practices within the upper Gucha watershed - a major contributor to the Lake Victoria catchment. With a population growth rate of $2.75 \%$ per annum and poverty level of $51 \%$ and average population density of 874.7 persons per $\mathrm{km}^{2}$, this watershed is characterized with land fragmentation and clearing of primary vegetation within the river valleys and swamps for agricultural space. The methodology involved digital contour map preparation, by georeferencing and digitizing, DEM generation and watershed delineation. Slope map, Stream network and flow direction maps of the watershed were generated as management tools. Using Satellite imageries of years 1990, 2000 and 2013, change detection was done. The results include change detection map, a DEM, slope map and flow direction map of the watershed for visualization of topographic characteristics of the watershed as tools for informed decision making by managers during conservation and management process. Conclusions appreciate and recognize the importance of spatial technologies in watershed conservation and management and recommend their use in developing watershed conservation and management tools.
\end{abstract}

Key Words: GIS, Remote Sensing, Watershed, Conservation, Management

\section{Introduction}

A watershed is defined as natural Hydrologic entity that covers a specific area of land surface from which rainfall runoff flows to a defined drain, channel, stream or river at any point (UNEP, 1990)". Watersheds are hydrologic units considered to be efficient and appropriate for the assessment of available resources within an area thus influencing subsequent planning and implementation of various development programs within that area. Hence, all the basic natural resources within a watershed like soil, water and vegetation in the hydrological entity of a watershed area should be managed sustainably.

Environment and development issues are considered the most important drivers of human welfare on the Earth surface. These two aspects are the main determinants of human welfare in terms of prosperity and survival. However, history is witness to the fact that many a time development issues are given priority than those of environmental conservation. This is mostly because human survival is an immediate and therefore 'an urgent' issue and the environment takes time to exhibit 'stress' - but indeed threatens the very human survival that 'human greed' tries to address in short term - development.

There is a struggle between general productivity and hence on economic development and environmental 'health' sustainability. In developing economies, about $80 \%$ of population reside in the rural areas and rely on the natural resources of land and water for day -to-day livelihood (Karanjit 1998). Coupled with population pressures on landscapes through agricultural practices, and other socio - economic activities, this has put a lot of pressure on watershed components especially water and vegetation cover. Land managers are continually looking for new methods for managing and monitoring watersheds and their components.

Population explosion in rural areas tempered with limited knowledge on agricultural 'good practices' implies more land degradation, higher poverty levels and health problems. This situation demands for prudent management of available resources, both natural and man-made, especially watersheds and wetlands. This can only be achieved by employing the right technology. The ability of Geospatial Information Systems (GIS) and Remote Sensing technologies in data capture, storage, analysis/querying and displaying has proved to be fast, accurate and cheap thus useful tools for environmental conservation and management (Chang, 2009).

The integration of technologies such as Geospatial Information Systems (GIS) and Remote Sensing, within the management of the natural boundaries of a drainage area of any ecosystem is important for optimum 
development of land, water and plant resources to meet the basic needs of man and other animals (domestic and wild) in a sustainable manner - this is part of a Watershed Management process.

Diversity in physical landscape results in different classes of land, which are subjected to different types of utilization/land use to the maximum extent possible due to increasing pressure on land, for agricultural pursuits by the ever increasing population especially in rural areas. This has resulted in uncontrolled exploitation of resources resulting in unproductive or degraded land. Such degraded lands, which are currently underutilized, are continuously deteriorating due to lack of water and appropriate soil management practices or on account of natural cause are called Wastelands.

\section{The Gucha Catchment Problem}

The upper part of the Gucha River has been harnessed for water supply development for Kisii, Ogembo, and Keroka townships and other smaller towns, besides other domestic uses within the watershed. There are several small scale self-help and private water supply projects within the catchment. Population growth rate in this catchment is one of the highest in the country, being $2.75 \%$ per annum and poverty level of $51 \%$ (KBS 2009). The average population density of the larger Kisii District is 874.7 persons per $\mathrm{km}^{2}$, with Nyaura location in Keumbu division having an extremely high density of 3,135 persons per $\mathrm{km}^{2}$ (KBS, 2009) Part of the Gucha catchment lies in this location.

It is alarming that minimal primary vegetation exists in the upper Gucha Watershed with exception of river line valley floors and few remaining swamps. This is due to clearance to give way for crop cultivation and settlement. Most of the current vegetation found in the catchment is of secondary character. In recent years, even the primary vegetation that occurred within the river valleys has been cleared as a result of swamp reclamation to accommodate the swelling population (Ongwenyi et al 1985). The vegetation cover of the catchment presently being secondary in character consists of agricultural crops such as tea, coffee, maize, bananas, millet, beans, and pyrethrum to some extent. The Blue gum (Eucalyptus) is the most common in this watershed. Other activities like brick making are common within the watershed and may have serious environmental impacts on the watershed due to the amount of soil they consume and the landscape degradation they leave behind.

\section{The Study Area.}

Originating from Kiabonyoru area near Nyamira Town, the Gucha catchment is located on the southwestern part of Lake Victoria drainage area in western Kenya. The total area of the catchment is $2196 \mathrm{~km}^{2}$. Gucha River is among the tributaries of the greater Gucha - Migori River whose total drainage area is $5180 \mathrm{~km}^{2}$ (Ojany and Ogendo, 1986). Considering the Gucha-Migori River system as a whole, the Gucha catchment constitutes approximately $42 \%$ of the total catchment area of the Gucha-Migori River system (Ojany and Ogendo, 1986). The catchment covers large parts of Kisii and Nyamira counties with only a small portion occurring in Migori district in the South Nyanza region. It is important to note that though Nyamira Township sits right at the source of River Gucha, it does not get its water from it, but from river Eyaka which is part of the river Sondu catchment.

The study area is contained in three districts of the larger Kisii (Kisii, Gucha and Nyamira). It comprises of an upland watershed of the Gucha River, a major river of the Lake Victoria Basin. The river has its source in the eastern highlands of the larger Kisii District. It lies between longitude $34^{\circ} 37^{\prime} 00^{\prime \prime}$ and $35^{\circ} 01^{\prime} 00^{\prime \prime}$ East and latitude $00^{\circ} 24^{\prime} 00^{\prime \prime}$ and $00^{\circ} 59^{\prime} 00^{\prime \prime}$ South, while the altitude of the areas lies between $900 \mathrm{~m}$ and $2000 \mathrm{~m}$ above the mean sea level.It experiences two rainfall seasons within the year i.e. short rains that run from September to November and long rains that occur in February to June while temperatures range from $16^{\circ} \mathrm{C}$ to $27^{\circ} \mathrm{C}$. The study area is as shown in Figure 1. 


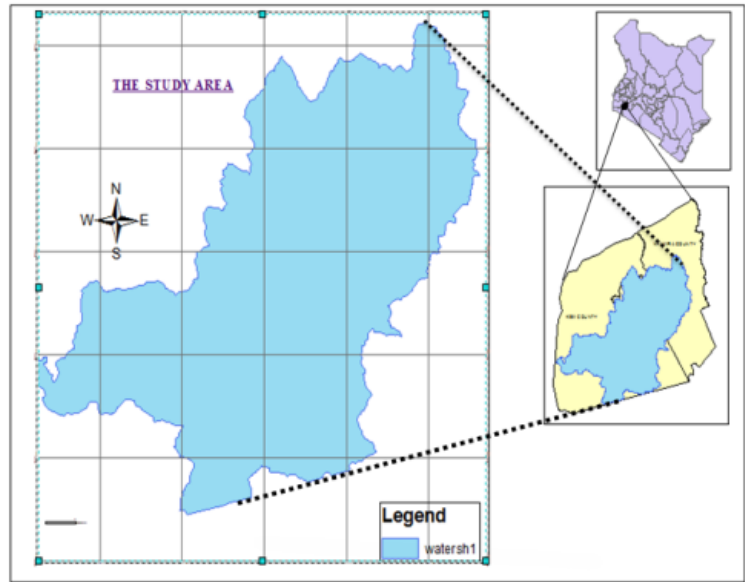

Figure 1. The Study Area within the larger Kisii

\subsection{Topographic Maps}

\section{Material and Methods}

Contour data for the study area was generated from Survey of Kenya Topographical maps of scale 1:50,000 with a $20 \mathrm{~m}$ interval, through digitizing process on an ArcGIS platform by Regional Centre for Mapping of Resources for Development (RCMRD). The data covering the study area was in two different shape files which were merged on a GIS platform to form one file and projected to Universal Transverse Marcator (UTM) projection so as to be in the same mapping zone as the area of study. The area of study lies in UTM Zone 36S, therefore the merged shape file was projected using datum Arc_1960_UTM_Zone_36S as shown in Figure 2(a).

Since the study area lies within the limits of the large Kisii area covering Nyamira and Kisii counties, the shape file of Kisii and Nyamira counties was extracted from the boundary map of Kenya acquired from the Independent Electoral and Boundaries Commission (IEBC) of Kenya. This shape file was used to clip the contours that lie within the large Kisii area in which the study area falls as shown in Figure 2(b) with the minimum elevation as $1130 \mathrm{~m}$ and the maximum elevation as $3040 \quad \mathrm{~m}$

(a)

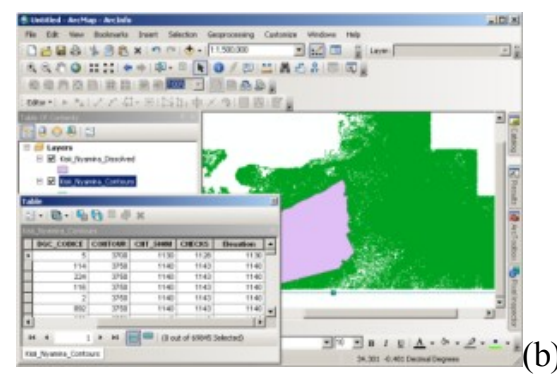

(b)

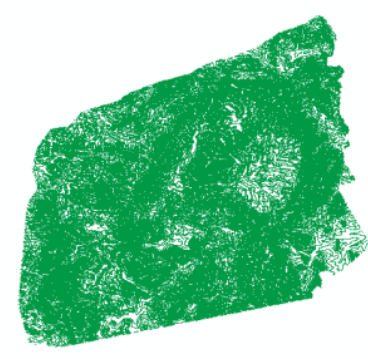

Figure.2 Clipping Process (a) and the Clipped Contours of the larger Kisii (b)

\subsection{DEM Preparation and Generation.}

The DEM is the base from which a watershed is delineated. This is achieved through the hydrological extension of the ArcGIS platform. It requires the right hardware in terms of capacity. The hardware should be checked whether it meets the specifications, since a DEM takes a lot of computer storage space and requires a computer with a favourable processing speed. In this case a computer with the following specifications was used; Windows 7, 64 bit, Core i5 CPU 2.4 GHZ, to generate a DEM for the larger Kisii area from which the area of study was clipped as shown in Figure 3 below. 
(a)

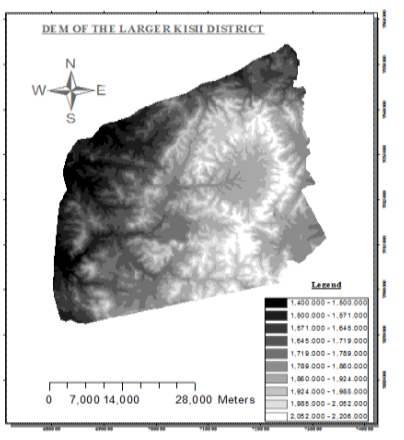

(b)

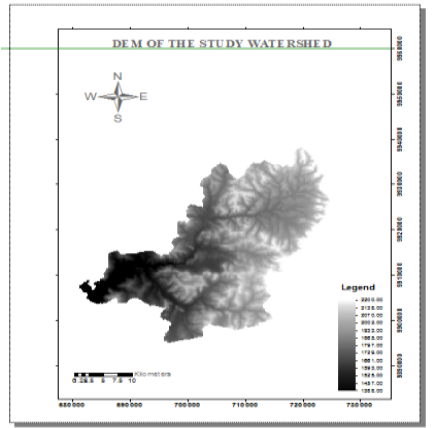

Figure. 3. DEM of the larger Kisii (a) from which the DEM of the study area was clipped (b).

\subsection{Watershed Delineation}

A watershed, also known as basins or catchments, was physically delineated by the area upstream from a specified outlet point. Watersheds can be delineated both manually on paper maps and digitally in a GIS environment through the hydrology extension. The process of delineating the Upper Gucha watershed from the larger Kisii DEM included the following procedures; Fill Digital Elevation Model, Create Flow Direction, Create Flow Accumulation, Create Watershed Pour Points, and Delineate Watersheds.

\subsubsection{Filling the DEM}

The 'Fill'tool in the 'Hydrologytoolbox' in Esri ArcGIS was used to remove any imperfections known as sinks in the digital elevation model. A sinkis a cell that does not have a defined drainage value associated with it. Drainage values indicate the direction that water will flow out of the cell, and are assigned when creating a flow direction grid for the landscape covered by the DEM. The resulting drainage network depends on finding the 'flow path' of every cell in the grid, so it is important that the fill steps be performed prior to creating a flow direction grid. The filled DEM was computed and added to the map as shown in Figure 4(a). There is a slight change to the values which is because the 'Topo to raster tool' in ArcGIS generates a hydrologically correct DEM.

\subsubsection{Creating a Flow Direction}

Direction of flow must be known for each cell, because it is the direction of flow that determines the ultimate destination of water flowing across the surface of the generated DEM. This is generated from the "filled DEM' through the GIS platform using 'Flow Direction tool' in ArcGIS environment as shown in Figure. 4 (a) and (b) below.

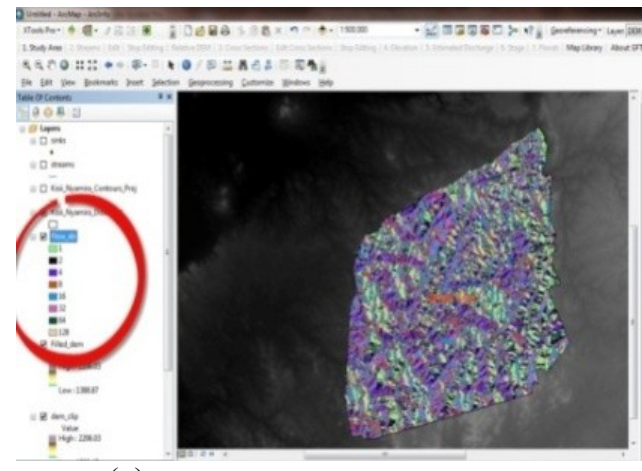

(a)

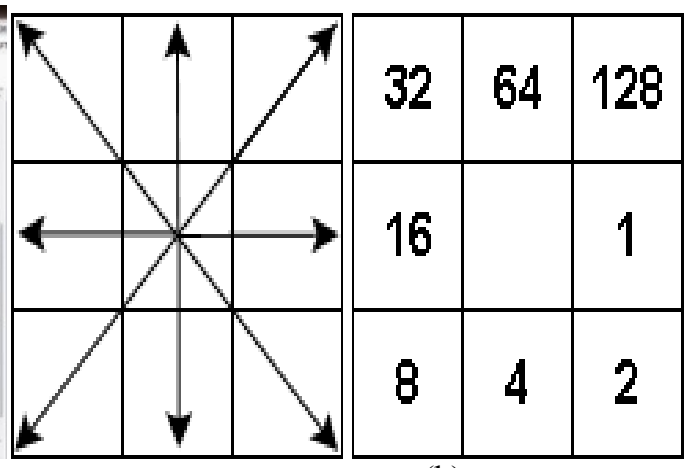

(b)

Figure.4 Flow direction map of the larger Kisii

The numbers in the Flow Direction layer in Figure 4(b) are generated automatically by the system to represent the flow direction, in this case, of water from each cell to its steepest down slope neighbour. 


\subsubsection{Creating Flow Accumulation}

This is a function in a GIS environment that calculates the flow into each cell by accumulating the cells that flow into each down slope cell. Flow Accumulation tool under Hydrology is used and flow direction raster in Figure 4(a) above was used as input data. The flow accumulation raster was computed and added to the DEM.

\subsubsection{Creating Watershed Pour Points}

This was accomplished by creating a new empty shape file to store the pour points identified for upper Guja River in the study area. The pour points are stored as the shape file name and the feature type as points. The Spatial Reference frame for the new pour points shape file is set to be the same as those of the existing DEM layer. The pour points are added by zooming in until the individual raster cells in the flow accumulation raster generated previously and edited accordingly as shown in Figure 5.

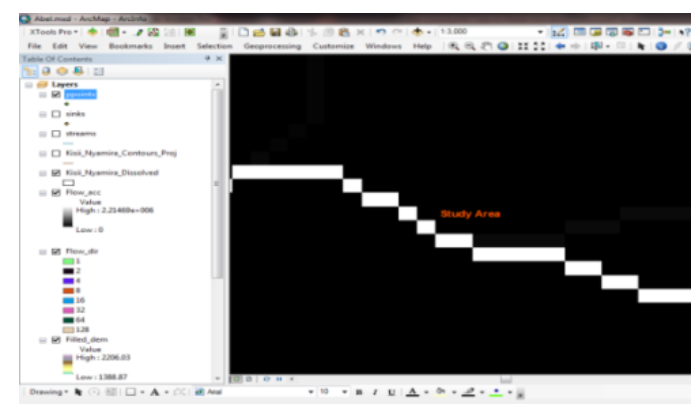

Figure 5. Watershed pour points

If the Analysis Extent and Cell Size do not match an existing layer, there will be problems of registration between the pour point raster and the other raster layers necessary to delineate watersheds. Therefore, it is always advisable to set the cell size and analysis extent area relative to an existing raster layer, in this case 'flow accumulation'.

\subsubsection{Delineating the Watershed/Study Area}

This is generated by Watershed generating tool and setting the flow direction grid as the input flow direction raster. By setting the raster version of the pour points as the input raster and the watershed is computed and generated as shown in the Figure 6.

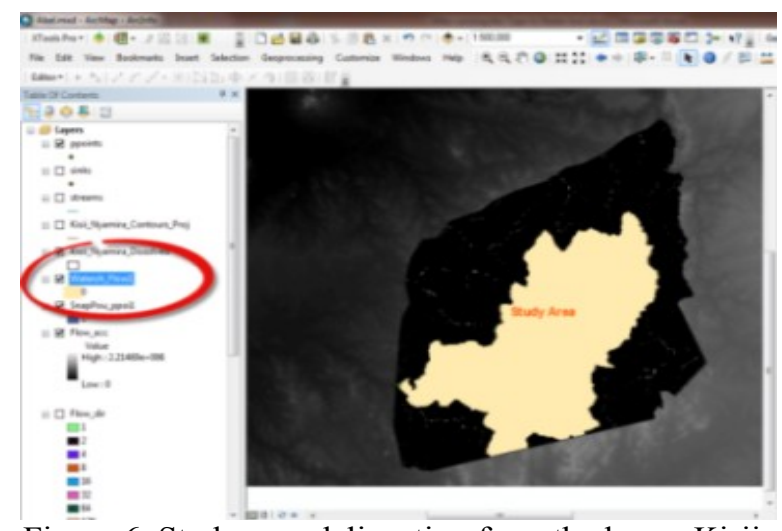

Figure 6. Study area delineation from the larger Kisii.

The watershed was polygonized to enable computation of the area and clipping of flow accumulation to the watershed so as to generate the contributing streams. It is from here that the calculation of the area of the watershed boundary polygon was done by adding a field to the watershed shape file and then using the 'calculate geometry tool'. The study area of Upper Gucha was computed and found to be $880 \mathrm{~km}^{2}$.

\section{Time Series Analysis of the Study Area}

For this study, three sets of Landsat TM satellite remote sensing data of the study area were acquired for the years 1990, 2000 and 2013, with a spatial resolution of $30 \mathrm{~m}$. Landsat 2010 image was omitted because of cloud and stripping challenges, it was replaced with Landsat 2013 image. The upper Gucha watershed is 
covered with four (4) scenes of the Landsat image. The images were prepared and processed in the Erdas version 9.1

\subsection{Image Preparation}

This refers to the processes of removing distortions and anomalies within the images that might hinder image classification hence affect analysis of the final results. As mentioned earlier, satellite data comes in different bands and covers different scenes of the earth surface. For this study scenes P169R060, P169R061, P170R060 and P170R061 were used. The study area lies at the intersection of the four scenes. Each scene was prepared separately by combining the required bands i.e. bands $1,2,3,4,5$ and 7 . This was done in an Erdas environment through a process known as layer stacking and was done in false colour combination.

To cover the study area, the four scenes covering the area had to be brought or combined together. This was also done in an Erdas environment through the process of mosaicking which made the four separate scenes to be one. This was done to images covering the three periods i.e. 1990, 2000 and 2013. The mosaic was reprojected to conform to the projection of the shape file of the area of study i.e. UTM zone 36 south (projection), Clarke 1880 (Spheroid), and a Datum of Arc 1960 (Kenya), from which the study area was subset using the Erdas version 9.1 environment as shown in Figure 7.

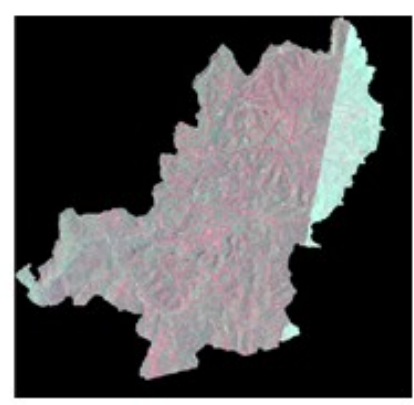

(a)

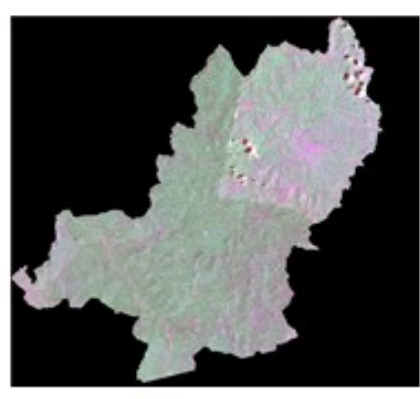

(b)

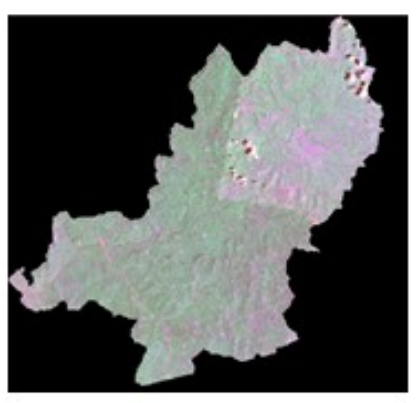

(c)

Figure 7. Satellite images of the study area - years 1990 (a), 2000 (b) and 2013 (c)

\subsection{Image Restoration, Rectification and Enhancement}

These are operations that were done to the image so as to correct for degradation of data within by removing systematic distortions and changing the image to the correct geometry to correspond with base map of the study area. Image restoration is important because it enhances scene illumination to bring out the variations of areas within the study area. It helps to deal with challenges such as shadows, and atmospheric conditions such as haze. Image correction technique was applied to the image to approximate the appearance of the above errors by estimating a replacement value based on the neighbouring pixel. There are two methods that corrects for atmospheric challenges - Physical modeling and empirical approximation.

Image rectification was done to the image by carrying out geometric correction by geo- referencing the image so as to deal with distortions arising from variations in altitude, velocity of the sensor platform and sensor characteristics. Geometric corrections can be done in two steps; by mathematical transformation developed to calculate geographic coordinates and resampling procedure which allows data from different satellites to be synchronized. In this study the mathematical approach was used with the nearest neighbour as the resampling method because it is simple, fast and does not change the original pixel value.

Image enhancement function was applied to the image so as to improve visual qualities of the image to assist in image interpretation by increasing visual distinctions among the features on the image. Algorithms that change the contrast brightness, the sharpness of the image and colour renditions of features in an image were applied. Two methods of enhancements were applied in this study - brightness and contrast by using histogram equalization to increase contrast over the whole image and edge enhancement to bring in contrast in linear features such as river channels.

\subsection{Image Classification}

Classification process was done using supervised classification technique which required training sites to be picked. This was done using the Area of Interest (AOI) tool. Training data was done for forestland, grassland, cropland and water bodies. When enough training sites were picked, (more than 600 pixels for each class), the classification was carried out using Maximum likelihood algorithm. The product was analyzed until 
pixel hygiene was achieved through iterations. The attribute table was populated and areas calculated and saved in a format that is compatible with most remote sensing software.

Change detection was performed in Arc Map 10.1 environment to determine which areas have changed. This was done between 1990 and 2000, 2000 and 2010, and 1990 to 2013. Maps showing land cover in the study area can be found in Kaburi and Odera (2014). We only give results of land cover change in this study.

\subsection{Stream Network of the Study Area.}

\section{Results}

For conservation and management processes of a watershed to be effective, it is important that all the contributing river channels are identified so as to get a clear picture on their sources, nature and most importantly, to identify the type of drainage pattern they form. This is important in understanding the geology of the watershed.

The upper Gucha watershed exhibits a dendritic drainage pattern which is a common most form of drainage pattern and looks like the branching pattern of tree roots. This type of drainage pattern develops in regions underlain by homogeneous geological material. The subsurface geology has similar resistance to weathering so there is no apparent control over the direction the tributaries take.The shape of a drainage pattern is depended on the topography of an area, the type of soil and bedrock, the climate, and vegetation cover which are very important components of a watershed. Dendritic drainage pattern is found where there are sedimentary rocks which are easily eroded. The drainage pattern of the Upper Gucha is Dendritic as shown in Figure 8.

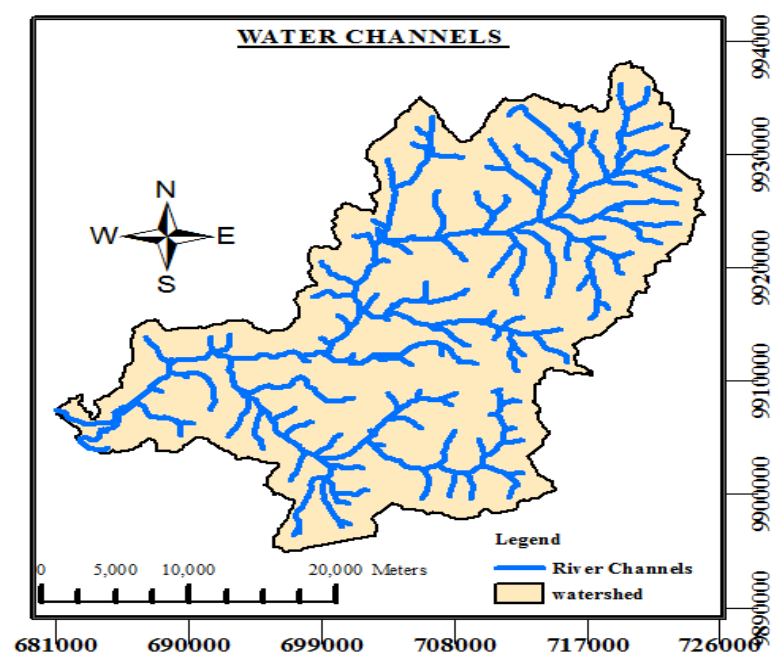

Figure 8. Stream Network of the study area.

\subsection{Slope Map of the Study Area}

A slope map shows the degree (steepness) of slope for a terrain (or other continuous surface). Aspect categories are symbolized using hues (e.g., red, orange, yellow, etc.) and degree of slope classes are mapped with saturation (or brilliance of colour) so that the steeper slopes are brighter (Cynthia A. 1993). This resulted in a map that has the colours of different categories to the aspect colour scheme; a gray category added to near-flat a slope that is represented without hue to encourage the interpretation that these areas had no aspect.

The source of Gucha River is generally compounded by several hills making it look like a basin. This is important in conservation issues because it can assist in identifying steep slopes and other hot spots for conservation and rehabilitation through examining the steepness and direction of slope,identifying areas at risk for landslides, fires and other hazards within a watershed,Identifying places of conservation and restoration within a watershed among many uses. The slope map of the Upper Gucha is as shown in Figure 9. 


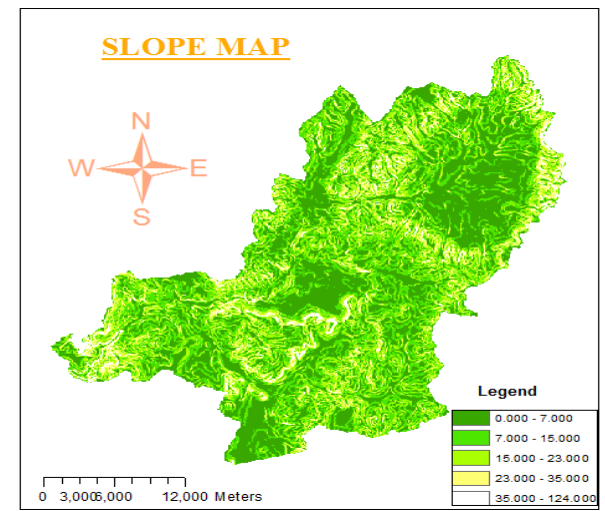

\subsection{Flow Direction Map of the Study Area}

Figure 9. Slope Map of the Upper Gucha catchment

In a (sink-free) Digital Elevation Model (DEM), the Flow direction operation determines, into which neighbouring pixel any water in a central pixel will flow naturally. Flow direction was calculated for every central pixel of input blocks of 3 by 3 pixels, each time comparing the value of the central pixel with the value of its 8 neighbours. The output map contains flow directions as N (to the North), NE (to the North East), etc. One can choose whether you wish to calculate the flow direction for the central pixels:

- by steepest slope: find the steepest downhill slope of a central pixel to one of its 8 neighbour pixels, or

- by lowest height: simply find the neighbour pixel that has the smallest value of all 8 neighbours, while this value should also be smaller than the value of the central pixel.

The Steepest Slope method was used; height differences were calculated for each block of $3 \times 3$ input pixels between the central pixel and the 8 neighbours.To compensate for distances, the height difference values of the 4 corner neighbouring pixels were divided by 1.4 while the height difference values of the 2 horizontal neighbours and the 2 vertical neighbours were divided by 1 then, the neighbour with the largest downhill slope steepness value was found. The position of this neighbour determines the flow direction of the current central pixel. The flow direction map was generated as shown in Figure 10 below.

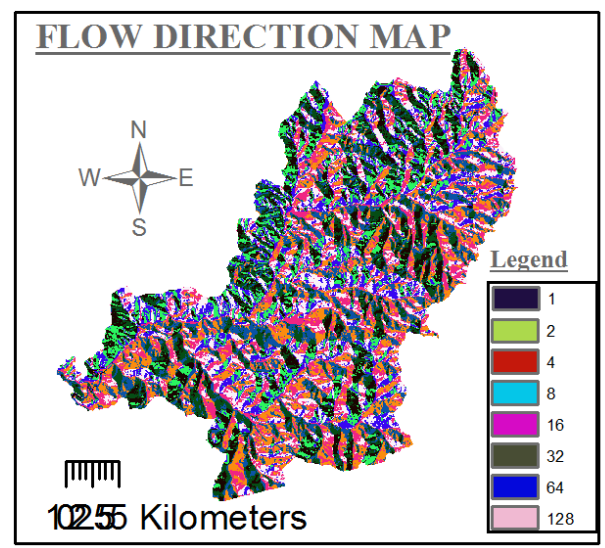

Figure 10. Flow direction map of upper Gucha catchment.

\subsection{Land Cover Changes}

The land cover changes reveal various shifts in land use within the Upper Gucha catchment in the period under consideration. While forest land and Grassland is dwindling drastically in percentage, Cropland is increasing very fast. Forest land decreased from $17.9 \%$ in 1990 to $14.5 \%$ from 1990 to 2013 , while Grassland has decreased from $3.1 \%$ in 1990 to $0.13 \%$ in 2013. This can be attributed to the rapid increase and demand for cropland for agricultural activities, which has increased from $78.8 \%$ in 1990 to $85.1 \%$ in 2013 . This can be attributed to the rapid increase and demand for crop land for agriculture as shown in Table 1 below. 
Table 1. Land cover changes.

\begin{tabular}{|l|l|l|l|l|l|l|}
\hline & \multicolumn{2}{|c|}{1990} & \multicolumn{2}{c|}{$\mathbf{2 0 0 0}$} & \multicolumn{2}{c|}{$\mathbf{2 0 1 3}$} \\
\hline Categories & Area (ha) & Area (\%) & Area (ha) & Area (\%) & Area (ha) & Area (\%) \\
\hline Forestland & $15,777.67$ & 17.849 & $16,551.54$ & 18.735 & $12,818.52$ & 14.502 \\
\hline Grassland & $2,769.30$ & 3.133 & $1,350.09$ & 1.528 & 111.06 & 0.126 \\
\hline Cropland & $69,642.72$ & 78.786 & $70,181.55$ & 79.440 & $75,239.64$ & 85.123 \\
\hline Water Bodies & 204.57 & 0.231 & 262.17 & 0.297 & 219.6 & 0.248 \\
\hline
\end{tabular}

\section{Conclusions and Recommendations}

This study presents the topographical characteristics and the analysis of the impacts of human activities on watersheds using GIS and Remote Sensing with a focus on the Upper Gucha catchment. The paper outlines an overview of environmental issues pertaining to watersheds, the relevance of GIS and Remote Sensing, the current trends and the state of the ecosystem within the watershed with regard to agriculture and urbanization. This is followed by an outline on the need to adopt an integrated water resource management system in the Upper Gucha catchment by employing the spatial technologies, with some emphasis on the growing threats posed by ecological degradation due to population pressures and widespread presence of environmental stressors. The others include the rise in socioeconomic activities especially the need for more agricultural land at the expense of forest land and open lands, impacting on the stability of natural ecosystems. However, the study recommends more research in the area by employing other spatial techniques like modeling the socio-economic and environmental concerns within the watershed.

Several conclusions can be drawn from this study. Agricultural activities comprise the large part of land cover of the Gucha catchment region. Though there is competition between agricultural activity and other components over space, the study finds 'no danger' in terms of land cover issues in the watershed as pertains to the general climatic change (since agriculture is land cover). Indeed this may explain why this region has been having almost consistent seasons in this era of climatic changes. However, agriculture has got its own challenges especially in terms of inputs and methods practiced. Agriculture in itself can be a threat depending on how it is practiced. This calls for concerted efforts to identify vulnerable spots especially slopes, swamps and vallies so that they can be rehabilitated and conserved. This can only be achieved by raising the spectra of responsibilities for planners and those charged with watershed management in the counties of Nyamira, Kisii and neighbouring counties along which the watershed traverses.

Spatial technologies and their ability to locate environmentally vulnerable spots in time and space, analyzing the spatial diffusion of ecological stressors known to influence watershed impairment in the Upper Gucha catchment in various ways will continue to be fast and effective. Accordingly, GIS and Remote Sensing techniques as used here provide decision support mechanism for managers in the assessment of environmental risks prompted by human activities along not only in the Upper Gucha but also in other watersheds. From the analysis on the Upper Gucha, the negative environmental impacts ravaging the watersheds by human activities appear predicated on pressures from demography, intense farming and the proliferation of urban development, besides externalities from municipal and industrial activities.

\section{Acknowledgements}

The digital elevation model used in this study was originally provided by the Regional Centre for Mapping of Resources for Development (RCMRD). The first author is grateful to Jomo Kenyatta University of Agriculture and Technology (JKUAT) for the support granted to him to carry out this research.

\section{References}

[1]. Kaburi A. N. and Odera P. A., (2014), Mapping and Analysis of Land cover Changes in the Upper Gucha Catchment using GIS and Remote Sensing. Proceedings of the International Conference on Sustainable Research and Innovation (SRI), JKUAT, Kenya, pp. $172-177$.

[2]. Chang K. T., (2009); Introduction to Geographic Information Systems. McGraw-Hill co.

[3]. Cynthia A. Brewer and Ken A. Marlow, (1993); Color Representation of aspect and Slope Simultaneously: Proceedings, Eleventh International Symposium on Computer-Assisted Cartography (Auto-Carto-1 1), Minneapolis, October/November, pp. 328-337.

[4]. Karanjit S., (1998); Remote Sensing and GIS in Watershed Area Management; Free Lance Environmental Consultant and Part time Trainer; Institute of Environmental Management. Nepal.

[5]. KBS, (2009); National Census; Government Printers, Republic of Kenya.

[6]. Ongwenyi G. S., Kitheka J. U., and Nyangaga M., J.,(1985); A preliminary account of the Lake Victoria drainage basin; A consultancy paper to Lake Basin Development Authority - Kenya.

[7]. Ojany, F. F. and Ogendo, R. B., (1986): A Study in Physical and Human Geography; Longman, Kenya.

[8]. UNEP, (2009); Integrated Water Resource Management Definition; International Decade for Action 'WATER FOR LIFE' 2005 2015. 